Review article

\title{
Research on media framing of public policies to prevent chronic disease: A narrative synthesis
}

\author{
Samantha Rowbotham ${ }^{\mathrm{a}, \mathrm{b}, *}$, Merryn McKinnon $^{\mathrm{c}}$, Leah Marks ${ }^{\mathrm{a}, \mathrm{b}}$, Penelope Hawe ${ }^{\mathrm{a}, \mathrm{b}}$ \\ ${ }^{\text {a }}$ Menzies Centre for Health Policy, School of Public Health, The University of Sydney, NSW 2006, Australia \\ ${ }^{\mathrm{b}}$ The Australian Prevention Partnership Centre, Australia \\ ${ }^{\mathrm{c}}$ Australian National Centre for the Public Awareness of Science, Australian National University, ACT 2601, Australia
}

\section{A R T I C L E I N F O}

We dedicate this work to our colleague, mentor, and above-all, our friend, Associate Professor Sonia Wutzke (1970-2017). The public health community is richer for having had you as one of its most passionate advocates.

\section{Keywords:}

Chronic disease

Policy

Framing

Media analysis

\begin{abstract}
A B S T R A C T
Media coverage plays a key role in shaping public and political attitudes towards policy interventions to improve health. We reviewed studies of news media to identify the arguments used to frame policies that address risk factors for chronic disease, and the impact of different arguments on attitudes to policy. Drawing on a previous scoping review, we identified a subsample of 49 studies of media framing of policies to address risk factors for lifestyle-related chronic disease for further analysis. We extracted and synthesised data to explore key themes. Of the limited research that has been undertaken, most studies have focused on tobacco policy, followed by alcohol, with a small number of studies of food and beverage policies. Studies have primarily used content analysis. Our synthesis demonstrated that advocates and opponents draw on five frames: health, social, economic, practical and ideological. Only a small number of studies have examined the impact of framing on public attitudes towards policy interventions, although such studies have tended to focus on the impact of how problems, rather than solutions (i.e. policies) are framed. Media research is crucial to understanding the complex ways in which attitudes towards policy interventions shape, and are shaped by, public discourses and can provide public health advocates with insights into strategies to successfully position policy arguments. This review highlights key insights and gaps in the hope that this will stimulate further research that will enhance public health advocates' abilities to promote effective public health policy.
\end{abstract}

\section{Introduction}

Chronic diseases, such as diabetes, cancer, and coronary heart disease are the leading cause of death and disability globally (World Health Organization, 2014). Much of the burden of disease could be prevented or ameliorated by reducing exposure to modifiable risk factors, including tobacco use, alcohol consumption, poor diet and physical inactivity (Australian Institute of Health and Welfare, 2016). Despite increasing recognition of the urgent need to tackle chronic diseases (Bloom et al., 2012) and growing evidence for both the effectiveness and cost-effectiveness of prevention (Vos et al., 2010), significant progress has not yet been made.

Effective intervention to prevent chronic disease requires comprehensive, multi-sectoral public health action that considers the social, economic and environmental factors that contribute to chronic disease (World Health Organization, 2013; Wutzke et al., 2017). Population level actions, including policies such as nutritional labelling, tobacco plain packaging, product reformulation, the provision of active modes of transport, or taxes on unhealthy foods have significant capacity to prevent chronic disease and improve quality of life (Kothari et al., 2013; Mayes and Armistead, 2013; Nutbeam and Kickbusch, 1998). Such approaches aim to effect change within the system and focus on reshaping social norms and conditions rather than relying upon individual behaviour change.

Despite the potential value of policy interventions, such approaches are often contested in public and political discourse and criticised as paternalistic or impinging upon individual liberties (Magnusson, 2015; Moore et al., 2015). This narrative represents a significant barrier to advocates seeking to advance public health policy on the political agenda, as public attitudes play an important role in shaping government action (Burstein, 2003; Page and Shapiro, 1983; Soroka and Wlezien, 2010). For example, in a review of the evidence on the impact of public opinion on policy, Burstein (2003) concluded that "public opinion affects policy three-quarters of the times its impact is gauged;

\footnotetext{
* Corresponding author. Menzies Centre for Health Policy, School of Public Health, The University of Sydney, NSW 2006, Australia.

E-mail addresses: samantha.rowbotham@sydney.edu.au (S. Rowbotham), merryn.mckinnon@anu.edu.au (M. McKinnon), leah.marks@sydney.edu.au (L. Marks), penny.hawe@sydney.edu.au (P. Hawe).
} 
its effect is of substantial policy importance at least a third of the time" (p. 36). Achieving progress in chronic disease prevention and public health more broadly is therefore likely to require the active involvement and support of both the public and policymakers (Australian Public Service Commission, 2007; Frieden, 2014).

News media lies at the nexus of the public and political agenda, and news coverage of issues and events both shapes and reflects public and political attitudes towards chronic disease prevention (Akintola et al., 2015; Otten, 1992). The selection of particular news stories lends salience to certain issues while the framing of such issues can promote particular interpretations of the problem, its causes and potential solutions (Entman, 1993). Research shows that the nature of information conveyed through the media, including what gets reported and how it is represented can have a powerful effect on public knowledge, attitudes, and behaviours (Anderson et al., 2009; Fan, 1996; Tewksbury and Scheufele, 2009). For example, Fan (1996) found that media framing of drugs as a 'crisis' in the American media resulted in changes in public perceptions of drugs as a problem. Research also indicates that policy attention rises and falls with changes in media coverage, rather than in response to changes in the actual size of the problem (Kitzinger, 2004). Media coverage in turn plays a crucial role in the agenda setting process by influencing policy makers' perceptions of policy issues, their urgency and the acceptability of policy solutions (Hawkins and Holden, 2013; Russell et al., 2016; Weishaar et al., 2016). For example, Katikireddi et al. (2014) demonstrated how a change in the framing of alcohol as a policy issue in Scottish media enabled policy makers to consider minimum unit pricing as a feasible policy intervention that was subsequently adopted. By contrast, in the United Kingdom alcohol policy debates have been stifled by industry actors' strategic use of the media to minimise the problem of alcohol-related harm and further their underlying corporate interests (Hawkins and Holden, 2013). Understanding how preventive policies are framed within the media is therefore crucial to enabling public health advocates to frame policy interventions in ways that are likely to engender public and political support.

In recent years there has been a proliferation of research into the framing of issues related to chronic disease, including risk factors, causes and solutions in public discourse, particularly news media (Rowbotham et al., 2019). However, to date, there has been limited synthesis across this literature, particularly with regard to examining similarities and differences in how different policies are framed, and the potential impact of such framing on public attitudes. One important exception here is a recent scoping review by Weishaar et al. (2016), which sought to explore media representations of industry and their attempts to frame media debates around chronic disease. They found that media coverage of chronic disease tends to be dominated by two contrasting frames: 'market justice' which focuses on individual responsibility, and 'social justice' which highlights the need for population level intervention. They argue that the degree to which policymakers are persuaded by these different frames has implications for the kinds of policies they are most likely to adopt (e.g. the likelihood that they will adopt policies that regulate corporate behaviour).

Syntheses across studies of media framing are valuable for enabling transfer of learning and insights across policy issues. In particular, they allow public health advocates to draw on arguments that have previously been used in other policy areas, and to anticipate the arguments they may encounter from policy opponents. Within this article we sought to review and synthesise existing studies of media coverage of policies targeting key risk factors for chronic disease. We aimed to identify patterns in how issues are framed across policies and risk factors and examine the potential impact of such arguments on public attitudes towards policy interventions.

\section{Methods}

This study builds on an earlier scoping review of the literature on media portrayal of issues related to chronic disease prevention
(Rowbotham et al., 2019). We examined a subset of articles from the original scoping review to explore in more depth how policies addressing risk factors for chronic disease have been framed within the media, and the impact of such framing on attitudes towards policy interventions. Full details of the original search process are reported elsewhere (Rowbotham et al., 2019) and are summarised in the Supplementary Materials.

\subsection{Identification of articles}

The original scoping review contained 499 studies. To identify the subset of studies to be synthesised within this paper we first identified studies about policy interventions in news media or the impact of exposure to news media on beliefs or attitudes towards policy interventions. Then, we ran title and abstract searches using keywords (policy, regulation, tax, legislation, law) to identify additional relevant articles. We reviewed full-texts of all identified articles $(n=86)$ and included articles that 1 ) were focused on policy interventions to address the major risk factors for chronic disease (smoking, alcohol, physical inactivity, nutrition, or obesity), and 2) either contained an analysis of news media (newspapers, magazines, online news, TV news or radio news) coverage of policies for chronic disease prevention or considered the effects of message framing on public attitudes towards policy for chronic disease prevention. Two reviewers (SR and MM) independently reviewed the full-texts of all identified articles against the inclusion criteria and disagreements were discussed and resolved. Of the original 86 articles, 49 were retained for analysis.

\subsection{Data extraction}

We developed a data extraction template to extract key study characteristics, research focus, sample and methods, media channel, and health topics and policies covered. We also extracted more detailed information on the findings of each study, particularly relating to sentiment (i.e. degree to which media coverage supports or opposes policy intervention) and framing of media coverage. As this was a secondary analysis, data extraction focused on the key findings as reported by the papers in our sample, with data being drawn from the results sections of included papers. Where multiple frames were presented within a single article, we extracted each of the frames reported, along with data on the frequency of each frame. We tested data extraction forms before use, and continually refined these during data extraction. One reviewer (MM or LM) extracted the details of each full-text article and another reviewer (LM or SR) checked extracted data to ensure consistency in the information extracted.

\subsection{Data synthesis}

We took a thematic approach (see Braun and Clarke, 2006) to data synthesis, and coded data inductively to identify key themes across studies. In synthesising the data, we focused primarily on how policy issues were framed. We began with free coding of the extracted data followed by synthesis of data into key themes and sub-themes. One researcher (SR) performed data synthesis in an iterative manner, continually revisiting extracted data and the original studies in light of emerging themes. In identifying key themes, we sought out patterns both within and across topic areas in order to capture the similarities and differences in how these issues have been framed. We refined the final set of themes through ongoing discussion with the research team.

\section{Results}

\subsection{Description of the sample}

Of the 49 included studies the majority focused on smoking $(n=26)$ or alcohol $(n=12)$. The majority were conducted in the United States $(n=26)$, followed by Australia $(n=13)$, and the United 
Kingdom $(n=5)$. The earliest study in our sample was published in 1997, and the number of studies increased steadily over time (see Fig. 1).

The majority of studies were analyses of media coverage of policy issues $(n=42)$ and employed content analysis to explore key themes in policy coverage. There were three main topic areas that were the focus of studies within our sample: tobacco, alcohol and nutrition, and studies varied in terms of whether they considered media coverage of general policy issues within a topic area or specific policy interventions (e.g. alcohol pricing, smoke free bar laws). See Table 1 for a summary of specific policies covered by the studies in our sample for each of the three topic areas. A small number of studies $(n=9)$ examined the impact of framing on public attitudes towards policy intervention. ${ }^{1}$ We discuss the synthesised findings from these two subsets of studies separately below. Table 2 provides a summary of the included studies (for characteristics of all included studies see Supplementary Materials).

\subsection{Media coverage of policy issues}

\subsubsection{Media sentiment towards policy intervention}

Twenty-nine studies considered media sentiment, i.e. the degree to which media coverage was supportive of, neutral or opposed to policy intervention (see Fig. 2 for an overview). Across these studies, coverage was predominantly supportive both for regulation in general and of specific policies (see Fig. 2). For example, concerning alcohol policy, Fogarty and Chapman (2012a) found $63.5 \%$ of Australian news coverage was supportive of advertising restrictions as part of alcohol policy. Other alcohol policies receiving predominantly positive sentiment included general alcohol regulation (Azar et al., 2014), alcopop tax (Fogarty and Chapman, 2011), and minimum unit pricing (Patterson et al., 2015a).

Coverage of diet and nutrition policies, such as regulation of fast food advertising (Henderson et al., 2009), and banning trans-fat (Wise and Brewer, 2010) was also predominantly supportive or neutral. However, across the studies in our sample, sentiment towards sugarsweetened beverage (SSB) tax was mixed; while Niederdeppe et al. (2013) found coverage to be more often supportive, Donaldson et al. (2015) found that most stories in their analysis framed the issue in oppositional terms.

Coverage of general tobacco control issues was predominantly supportive (e.g. Durrant et al., 2003; Long et al., 2006; McGee et al., 2014), with only a small number of studies finding predominantly mixed/neutral coverage (Bach et al., 2013; Blake et al., 2015) or opposing coverage (Wakefield et al., 2003). However, sentiment towards specific tobacco control policies varied depending on policy type, with coverage of bans on smoking in cars (Freeman et al., 2008; Hilton et al., 2014; Patterson et al., 2015b), smoke-free parks and beaches (Moshrefzadeh et al., 2013), smokeless tobacco control (Wackowski et al., 2013), and tobacco tax (Thrasher et al., 2014) being predominantly supportive. Sentiment towards smoke-free bars and restaurants was mixed, such that while some studies found coverage to be generally supportive (Champion and Chapman, 2005; McDaniel et al., 2015), others found the majority of coverage to be opposed to the policy (Magzamen et al., 2001; Nagelhout et al., 2012).

\subsubsection{Framing of arguments for and against policy interventions}

We identified five overarching frames used to argue for and against policy interventions within the studies in our sample. These included the likely health, economic and social impacts of policy interventions, the practical aspects of policy, and ideological arguments. Table 3 provides a synthesis of the key arguments for and against policy intervention for each policy area (smoking, alcohol and processed food/

\footnotetext{
${ }^{1}$ Two studies included both an examination of media coverage and consideration of the impact of framing on attitudes towards policy intervention.
}

soft drinks) and the following sections elaborate on the key arguments in more detail.

3.2.2.1. Health framing. As indicated in Table 3, arguments about health risks and benefits featured prominently in support of policy interventions, particularly for tobacco control. This included highlighting the risks of tobacco to health, for example, the assertion that smoking kills and/or is linked to specific illnesses. Similar arguments also frequently appeared in studies of media framing of alcohol and nutrition policies. For example, Niederdeppe et al. (2013) found that $77 \%$ of articles about SSB tax discussed the health consequences of SSB consumption, particularly the role of SSB in obesity and other health conditions, while Fogarty and Chapman (2012b) found that $75 \%$ of articles about alcohol regulation mentioned health effects, with a tendency to focus on acute, rather than long-term health effects.

In contrast, health frames were rarely used to oppose policy interventions, with the exception of a small number of studies that identified arguments about health benefits of alcohol and tobacco consumption. For example, some arguments proposed that smoking can assist with stress management (McLeod et al., 2009). Others downplayed the evidence of health risks, for example by arguing for a lack of evidence for the link between second hand smoke exposure and health (Champion and Chapman, 2005), or between SSB consumption and obesity (Niederdeppe et al., 2013).

3.2.2.2. Societal framing. Societal framing included arguments about the benefits and harms to society and the need for protection of particular groups within society. Implicit within such framing was the idea that the problems being targeted by policy are social problems, which require collective action beyond individual behaviour change. Protection of vulnerable groups was the most common argument invoked in support of policy interventions and most often centred on the need to protect children, although protection of other groups was also highlighted for some policies (see Table 3). For example, while arguments in support of policies to restrict smoking in cars or tobacco control in general focused on the need to protect children, those for smoke free bar laws focused specifically on protection of hospitality workers. Lima and Siegel (1999) found that arguments about the need to protect children appeared in $81 \%$ of articles related to tobacco control, and was the dominant theme in $55 \%$ of articles. Arguments in support of alcohol and nutrition policy often invoked the need for protection of other groups in addition to children, particularly the need for protection of low income populations and cultural minorities from being targeted as consumers and to reduce disproportionately high consumption in these groups. The use of other types of societal arguments differed according to the policy area, with discussions of alcohol policy considering the impact of alcohol consumption on families and communities in terms of increased crime, domestic abuse and antisocial behaviour, while studies of tobacco considered issues such as accidental fires, littering and public nuisance.

Societal framing was rarely used in arguments opposing policy interventions, except in discussions of taxation of tobacco and SSB, where a frequent argument was that the tax would disproportionately affect vulnerable groups, particularly those with low income.

3.2.2.3. Economic framing. Economic arguments centred on the potential impacts of policy on businesses, health revenue, and the general economy, and were invoked across all three policy areas (smoking, alcohol and nutrition), particularly in arguments opposing policy interventions. For example, arguments against smoking regulation included indoor smoking bans being damaging to businesses by leading to loss of customers; to individuals and the wider economy through job losses; to the economy as it benefits from money from the tobacco industry; and to businesses and the tobacco farming industry as a result of taxes on tobacco. Arguments against alcohol and food and beverage 


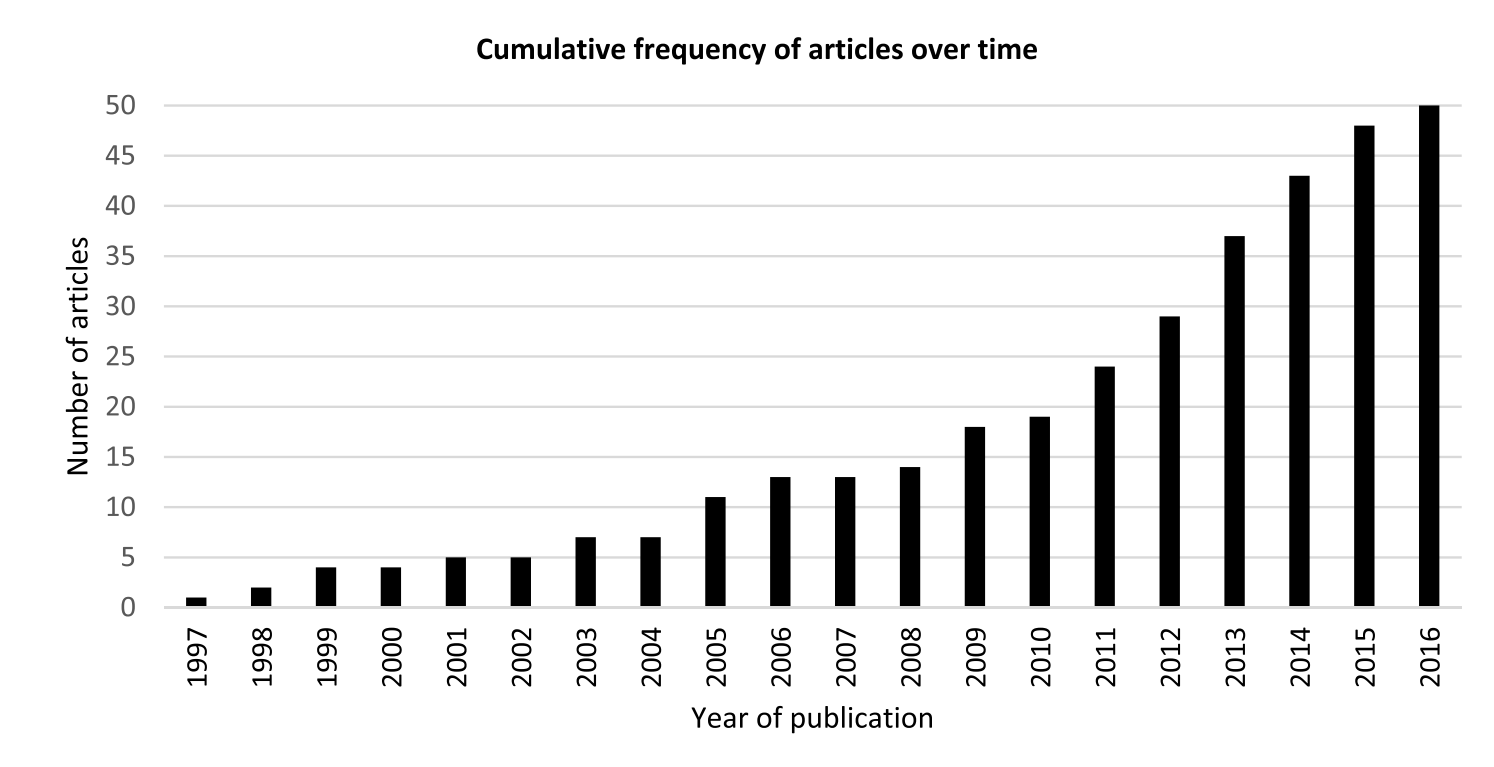

Fig. 1. Cumulative frequency of included studies of media framing of policy issues over time from 1997 to 2016.

Table 1

Overview of specific policies covered by studies within our sample.

\begin{tabular}{|c|c|}
\hline Health topic & Policies \\
\hline Alcohol & $\begin{array}{l}\text { - Alcohol advertising restrictions (Fogarty and Chapman, } \\
\text { 2012a) } \\
\text { - Alcopop tax (Fogarty and Chapman, 2011) } \\
\text { - Alcohol minimum unit pricing (Hilton et al., 2014; Patterson } \\
\text { et al., 2015; Wood et al., 2014) } \\
\text { - Alcohol outlet regulation (Lawhon and Herrick, 2013) } \\
\text { - Tax reductions on alcohol (Hellman and Karlsson, 2012) } \\
\text { - Alcohol warning labels (Lemmens et al., 1999) }\end{array}$ \\
\hline Smoking & $\begin{array}{l}\text { - Legislation to ban smoking in various locations, including: } \\
\text { o Vehicles carrying children (Freeman et al., 2008; Hilton et al., } \\
\text { 2014; Patterson, Semple, Wood, Duffy and Hilton, 2015) } \\
\text { o Bars and restaurants (Champion and Chapman, 2005; } \\
\text { Magzamen et al., 2001; McDaniel et al., 2015; Nagelhout } \\
\text { et al., 2012) } \\
\text { o Workplaces (Bach et al., 2013) } \\
\text { o Schools (Morrison et al., 2006) } \\
\text { o Casinos (Wackowski et al., 2011) } \\
\text { o Parks and beaches (Moshrefzadeh et al., 2013) } \\
\text { - Tobacco settlement (Lima and Siegel, 1999) } \\
\text { - Tobacco plain packaging (Freeman, 2011) } \\
\text { - Tobacco tax (Thrasher et al., 2014) }\end{array}$ \\
\hline Nutrition & $\begin{array}{l}\text { - Prohibit sale of SSB over } 16 \text { oz (Donaldson et al., 2015) } \\
\text { - Regulation of fast food advertising (Henderson et al., 2009) } \\
\text { - SSB tax (Niederdeppe et al., 2013) } \\
\text { - Trans fat ban (Jarlenski and Barry, 2013; Wise and Brewer, } \\
\text { 2010) } \\
\text { - Banning soft drinks and fast food in schools (Barry et al., 2013) }\end{array}$ \\
\hline
\end{tabular}

policies tended to focus directly on economic damage to businesses in terms of loss of revenue, for example as a result of alcohol licencing restrictions (Lawhon and Herrick, 2013) or the unfair impact of an SSB tax on small businesses (Donaldson et al., 2015).

Economic arguments in support of alcohol and tobacco policy tended to emphasise the economic costs of these behaviours. For example, Lima and Siegel (1999) found that $24 \%$ of articles identified smoking as a problem due to costs in healthcare and lost productivity, while McLeod et al. (2009) found that $10 \%$ of articles framed smokers as a drain on the economy. Economic arguments highlighting the positive benefits of policy for the economy, such as increased revenue, or that the policy would not be detrimental to business, were also frequently identified, often to counter arguments in opposition of policy on economic grounds.
Table 2

Characteristics of included studies.

\begin{tabular}{|c|c|c|}
\hline & $n$ & $(\%)$ \\
\hline \multicolumn{3}{|l|}{ Studies of media coverage of policy $(n=42)$} \\
\hline \multicolumn{3}{|l|}{ Media channel } \\
\hline Newspapers & 40 & $(95.2)$ \\
\hline Television & 10 & (23.8) \\
\hline Magazines & 3 & $(7.1)$ \\
\hline Online (incl. online news, web pages and social media) & 2 & $(4.8)$ \\
\hline Radio & 1 & $(2.4)$ \\
\hline \multicolumn{3}{|l|}{ Media sample timeframe } \\
\hline Less than 1 year & 5 & (11.9) \\
\hline $1-5$ years & 25 & (59.5) \\
\hline $6-10$ years & 8 & $(19.0)$ \\
\hline $11-15$ years & 3 & $(7.1)$ \\
\hline More than 15 years & 1 & $(2.4)$ \\
\hline \multicolumn{3}{|l|}{ Policy area } \\
\hline Smoking & 25 & $(59.5)$ \\
\hline Alcohol & 11 & $(26.2)$ \\
\hline Nutrition & 5 & (11.9) \\
\hline Other & 1 & $(2.4)$ \\
\hline \multicolumn{3}{|l|}{ Studies of media coverage on public attitudes $(n=9)$} \\
\hline \multicolumn{3}{|l|}{ Health topic } \\
\hline Obesity & 4 & $(3.6)$ \\
\hline Smoking & 3 & $(2.7)$ \\
\hline Alcohol & 1 & $(0.9)$ \\
\hline Nutrition & 1 & $(0.9)$ \\
\hline Diabetes & 2 & $(2.2)$ \\
\hline \multicolumn{3}{|l|}{ Study design } \\
\hline Experimental & 6 & $(6.6)$ \\
\hline Descriptive & 2 & $(2.2)$ \\
\hline Correlational & 1 & (1.1) \\
\hline \multicolumn{3}{|l|}{ Media type } \\
\hline Newspapers & 2 & $(2.2)$ \\
\hline Reader comments on online news & 1 & $(1.1)$ \\
\hline Constructed news stories & 6 & $(6.6)$ \\
\hline Total Articles & 49 & \\
\hline
\end{tabular}

3.2.2.4. Practical framing. Practical arguments were those that focused on the feasibility, appropriateness and likely efficacy of proposed policies, including public perception and 'acceptability' of proposed policies. Such arguments were frequently used to argue against policy interventions across all three policy areas, although arguments about the difficulties of policy implementation were particularly prominent in discussions of restricting smoking in cars and public places where issues of enforcement were frequently raised. Other arguments focused on the 


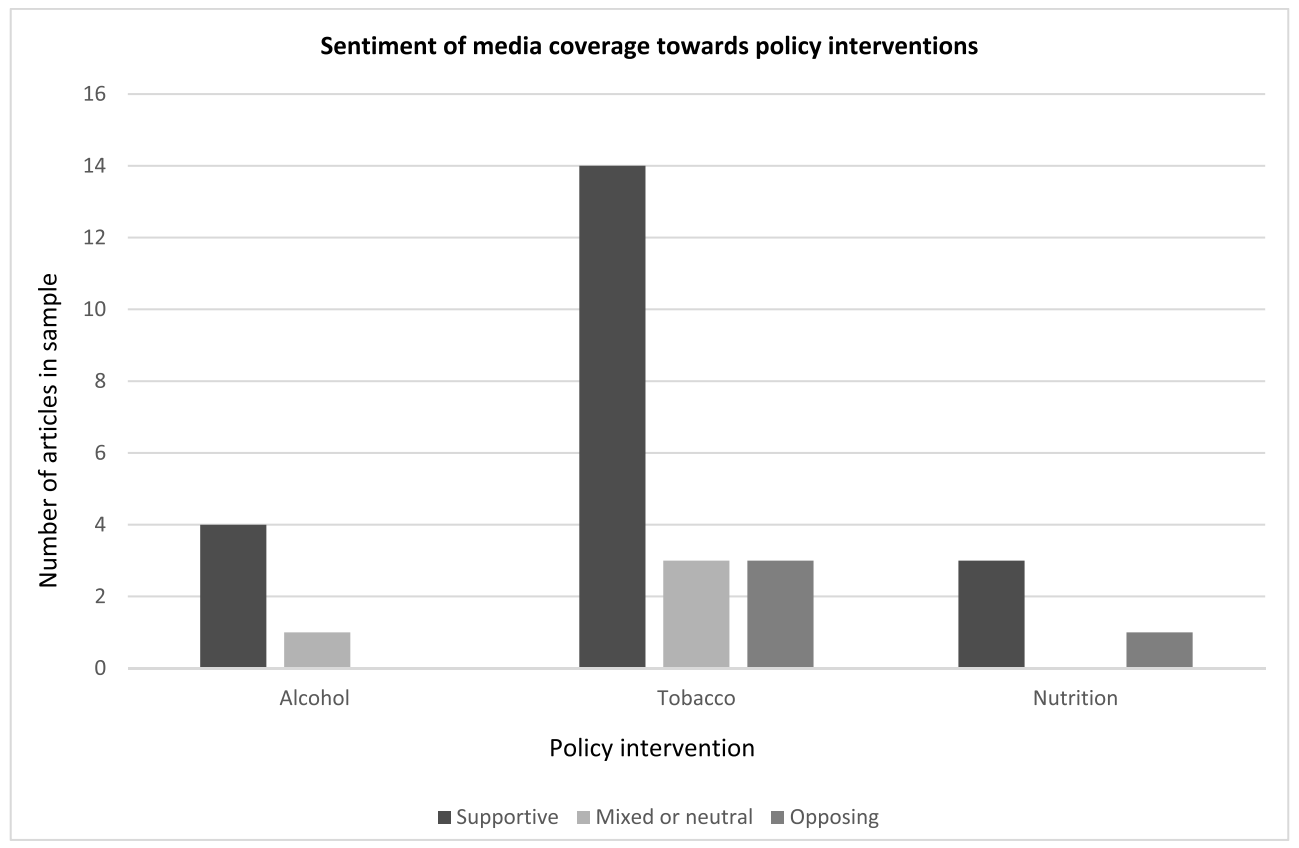

Fig. 2. Frequency of supportive, neutral or opposing sentiment of media coverage in three policy intervention areas from included sample $(\mathrm{n}=29)$.

likely (in)effectiveness of policy and could often be considered to contain an element of deflection from the issue at hand. For example, drawing on issues such as inappropriate targeting of the policy to the problem (e.g. that pollutants other than second hand smoke were more damaging to health); a lack of evidence that the policy would be effective; the likelihood of unintended negative consequences; or that other solutions (such as education) would be more effective. Arguments opposing the SSB tax for example, included that the policy was flawed because it did not cover all beverages or other unhealthy foods, that people could purchase refills (Donaldson et al., 2015), and that better solutions would include changes to school environments, community programs and mass education (Niederdeppe et al., 2013).

Examples of practical framing of arguments in support of policy were less frequently identified, although there were some examples of attempts to counter concerns about the feasibility and effectiveness of tobacco policy, as well as assertions of the likely success of and/or evidence for the effectiveness of smoking, alcohol and beverage policies.

3.2.2.5. Ideological framing. Cultural and ideological arguments included those that centred on the rights of individuals and organisations, cultural values, issues of responsibility including the role of government, and moral and ethical perspectives. Ideological framing differs from societal framing in that it focuses on the rights, values and ethics of individuals and organisations, rather than on benefits and harms to society. Such arguments were most frequently invoked in opposition of policy, particularly through arguments that individuals were responsible for their own behaviour and that policy interventions represented government overreach and interference and were the start of a 'slippery slope' towards further restriction on individual and commercial freedoms. Opponents of smoking and tobacco policies also employed arguments that such policies impinged on cultural values, such as the suggestion that smoking bans were 'unAustralian' (Champion and Chapman, 2005).

When used in support of policy interventions, arguments across the three policy areas tended to focus primarily on the need for government intervention to tackle unethical industry tactics such as aggressive marketing and promotion of unhealthy products, and the responsibility of government to protect the public and support them to make healthy choices. For example, Fogarty and Chapman (2012a) found 24\% of articles on alcohol advertising restrictions argued restrictions were necessitated by the disingenuous and deceitful alcohol industry and $16.6 \%$ supported the policy as an 'indispensable counter to pervasive advertising culture' (p. 6). This is distinct from the societal frame as the public here is not treated as a vulnerable population; rather the actions of corporations require regulation which is a government responsibility.

\subsubsection{Impact of framing of policy issues on public attitudes}

A small number of studies $(n=9)$ considered the influence of media framing on public attitudes towards policy interventions. The majority of these $(n=6)$ used experimental approaches to test the impact of exposure to different argument frames on attitudes towards policy interventions. For example, Barry et al. (2013) found that regardless of how the causes of childhood obesity were framed, participants were more likely to support obesity prevention policies when news reports identified an individual obese child than when the problem was described in more general terms. Another found that news stories that incorporated information on context, risk factors, prevention strategies, and social attributions of responsibility fostered more support for public policy change than those that emphasised individual responsibility (Coleman et al., 2011). Gollust et al. (2009) examined the interaction between political orientation and framing on policy support in the United States and found that framing type 2 diabetes in terms of social determinants of health resulted in higher levels of policy support amongst Democrats but reduced support amongst Republicans.

Only one study directly examined the impact of frames which supported versus opposed a specific policy initiative; the New York transfat ban policy (Wise and Brewer, 2010). The findings suggested that exposure to a pro-ban frame with a public health focus (negative effects of trans fats on health) increased support for banning trans-fat, while exposure to an anti-ban frame with a business focus (policy will harm business) reduced policy support.

One study used a correlational approach to explore the association between media exposure and policy support, finding that exposure to negative media coverage of smoke-free bar and restaurant legislation was associated with reduced support for the policy (Nagelhout et al., 2012). Another study found that alcohol legislation which received little or no press coverage were more likely to be successfully passed into law than those that received high press coverage (Harwood et al., 2005). Finally, one study examined reader comments posted in 
Table 3

Synthesis of key arguments used in framing debates about alcohol, smoking and nutrition policies.

\begin{tabular}{|c|c|c|}
\hline Frames & Alcohol & Smoking \\
\hline \multicolumn{3}{|l|}{ Health } \\
\hline \multirow[t]{2}{*}{$\begin{array}{l}\text { Arguments in } \\
\text { support of } \\
\text { policy }\end{array}$} & $\begin{array}{l}\text { Link between alcohol consumption and } \\
\text { health, including consequences of alcohol } \\
\text { consumption and alcohol related harms, } \\
\text { particularly the acute effects of consumption }\end{array}$ & $\begin{array}{l}\text { Link between smoking and health, including } \\
\text { harms such as cancer, death, and the addictive } \\
\text { nature of smoking. Health discussed in terms } \\
\text { of harms to both smokers and those exposed to } \\
\text { second hand smoke }\end{array}$ \\
\hline & $\begin{array}{l}\text {-Alcohol policy will have a positive impact } \\
\text { on health, e.g. by reducing the health harms } \\
\text { of over-consumption }\end{array}$ & $\begin{array}{l}\text {-Tobacco control policy will have positive } \\
\text { impact on health, e.g. the health benefits of } \\
\text { smoke-free air or reduction in harms as a result } \\
\text { of policy }\end{array}$ \\
\hline $\begin{array}{l}\text { Arguments } \\
\quad \text { against } \\
\text { policy }\end{array}$ & $\begin{array}{l}\text { Moderate alcohol consumption confers } \\
\text { health benefits, e.g. prevention of heart } \\
\text { attacks }\end{array}$ & $\begin{array}{l}\text { Downplays the risks to health, e.g. by citing } \\
\text { a lack of evidence for the link between } \\
\text { exposure to second hand smoke and adverse } \\
\text { health effects or portrayal of smokeless } \\
\text { tobacco as less harmful than smoking } \\
\text {-Smoking confers some health benefits, e.g. } \\
\text { assisting with stress management }\end{array}$ \\
\hline \multicolumn{3}{|l|}{ Societal } \\
\hline $\begin{array}{l}\text { Arguments in } \\
\text { support of } \\
\text { policy }\end{array}$ & $\begin{array}{l}\text { - Societal harms of alcohol, e.g. the } \\
\text { association between alcohol consumption and } \\
\text { harm to families and communities through } \\
\text { antisocial behaviour, domestic abuse, and } \\
\text { other criminal activity } \\
\text {-Societal benefits of alcohol regulation, e.g. } \\
\text { by limiting illegal trade, curbing abuse, } \\
\text {-Need to protect vulnerable groups, usually } \\
\text { with a focus on the protection of children and } \\
\text { young people from alcohol related harms, but }\end{array}$ & $\begin{array}{l}\text { - Societal costs of smoking, including nuisance } \\
\text { behaviour such as littering and fire, and that } \\
\text { smoking is harmful to society in general } \\
\text { - Need to protect vulnerable groups, } \\
\text { particularly protecting children, hospitality } \\
\text { workforce and population in general from } \\
\text { harms of second hand smoke exposure and } \\
\text { preventing young people from taking up } \\
\text { smoking. }\end{array}$ \\
\hline
\end{tabular}

Arguments
agains policy

Economic

Arguments in support of policy
- Economic costs of alcohol consumption to society, e.g. costs to health care system, criminal justice system and economy

- Policy will have a positive economic impact, e.g. will increase business revenue

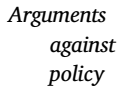

- Policy will harm businesses or the economy, e.g. through job losses and decreased revenue for businesses

- Alternatives to policy do not work, e.g. failure of education

-Policy is likely to be effective, e.g. citing evidence to support the effectiveness of the policy

-Policy is a sensible and appropriate response to the problem

-Policy is likely to be feasible in practice -Policy is appropriately targeted to the problem

-Public or political support for policy intervention

- Policy is not feasible in practice, e.g. will face legal challenges

-Lack of public support for policy intervention

-Policy is unlikely to be effective, e.g. citing lack of evidence for likely effectiveness or evidence that it will not be effective -Policy is not the appropriate solution, e.g. targeting the wrong groups of drinkers
Nutrition

- Link between dietary intake and health, e.g. between sugar consumption and obesity, cardiovascular disease, and other illnesses

-Policy will have a positive impact on health, e.g. decreasing obesity and reducing associated morbidity and mortality

- Downplays the risks to health, e.g. by citing a lack of evidence for or exaggeration of the adverse health effects of consumption

-Downplays the likely health benefits of policy, citing lack of evidence for impact of the policy on health

- Policy will protect vulnerable groups, particularly protecting children from harms of overconsumption, but also racial and ethnic minorities and low income populations

- Societal benefits of smoking, e.g. increasing opportunities for social interaction

- Smokers depicted as vulnerable population who will be harmed by policy, e.g. smokers are addicted to nicotine and should not be punished for finding it difficult to quit; impact of policy on low income groups

- Economic costs of smoking and second hand smoke exposure, e.g. health care costs and lost productivity (due to illness and smoking breaks)

-Policy will have a positive economic impact, e.g. may result in cost savings to businesses -Policy will not harm businesses or the economy, e.g. regulation will not lead to decrease in revenue or jobs

- Policy will harm businesses or the economy, e.g. by cutting earnings and causing job losses

- Alternatives to policy do not work, e.g. failure of education and 'softer' policy options such as designated smoking areas

- Policy is likely to be effective, e.g. citing evidence to support the likely efficacy of the policy

- Policy is likely to be feasible in practice, e.g. countering concerns about practicality of enforcing smoke-free policy

- Public or political support for policy intervention

- Policy is not feasible in practice, e.g. concerns about the practicalities and timing, difficulties with enforcement, including lack of resources

- Policy is unlikely to be effective, e.g. lacks evidence of likely effectiveness, calling into question the likelihood of change resulting from the policy, drawing on historical issues of policy change
- Policy will harm low-income groups, e.g. citing the regressive nature of taxes on soft drinks

- Policy will have a positive economic impact, spending

- Policy will not harm businesses or the economy e.g. alternatives (to trans-fat) are available and would not be more expensive

- Policy will harm businesses or the economy, e.g. policy will disadvantage small businesses

- Policy is likely to be effective, e.g. drawing on the comparison between sugar sweetened beverage and tobacco taxes

- Public or political support for policy intervention

- Policy is not feasible in practice, e.g. will be difficult to implement and enforce

- Policy is unlikely to be effective, e.g. failure of previous attempts to implement policy, flaws in policy (e.g. SSB tax doesn't cover all soft drinks)

- Policy is not the appropriate solution, e.g. other measures (e.g. education, school campaigns) would be more effective e.g. taxes will raise revenue for health care 
Table 3 (continued)

\begin{tabular}{|c|c|c|c|}
\hline Frames & Alcohol & Smoking & Nutrition \\
\hline & $\begin{array}{l}\text {-Unintended negative consequences of the } \\
\text { policy, e.g. increased alcohol consumption, } \\
\text { substitution for different alcoholic drinks, } \\
\text { redirection of where drinking occurs } \\
\text {-Policy is unnecessary because the alcohol } \\
\text { industry is a responsible industry that is } \\
\text { already engaged in self-regulation and is } \\
\text { actively managing alcohol risks }\end{array}$ & $\begin{array}{l}\text { Policy is not the appropriate solution, e.g., } \\
\text { other interventions (e.g. education campaigns) } \\
\text { would be more effective, policy has the wrong } \\
\text { focus (e.g. should focus on other sources of } \\
\text { environmental pollution) } \\
\text { Policy is unnecessary because industry is } \\
\text { already tackling the problem, e.g. through self- } \\
\text { regulation and this is working }\end{array}$ & $\begin{array}{l}\text { Policy is unnecessary because food industry is } \\
\text { already acting ethically and in line with social } \\
\text { responsibility and industry self-regulation is } \\
\text { sufficient } \\
\text { - Lack of public support }\end{array}$ \\
\hline \multicolumn{4}{|c|}{ Cultural or ideological } \\
\hline $\begin{array}{l}\text { Arguments in } \\
\quad \text { support of } \\
\text { policy }\end{array}$ & $\begin{array}{l}\text { Policy needed to combat industry tactics } \\
\text { such as pervasive advertising, branding, and } \\
\text { promotion of alcohol }\end{array}$ & $\begin{array}{l}\text { - Policy needed to combat industry tactics, } \\
\text { e.g. industry as evil, unethical and } \\
\text { manipulative, policy only way to combat } \\
\text { deceptive and manipulative tactics, tobacco } \\
\text { industry should be held to account for tobacco } \\
\text { related morbidity and mortality } \\
\text {-Government responsibility to protect } \\
\text { health of the public, also responsibility of } \\
\text { other stakeholders such as employers } \\
\text {-Policy is a legitimate use of government } \\
\text { powers } \\
\text {-Right of public to be protected from harms } \\
\text { of tobacco exposure at work and in public } \\
\text { places } \\
\text {-Stigmatisation of smoking as wrong, } \\
\text { irresponsible or deviant, and that 'selfish' } \\
\text { behaviour of smokers should not be allowed to } \\
\text { affect those around them }\end{array}$ & $\begin{array}{l}\text { Policy needed to combat industry tactics, } \\
\text { such as aggressive fast food marketing } \\
\text { - Responsibility of government to support } \\
\text { people to make healthy choices and to protect } \\
\text { health }\end{array}$ \\
\hline $\begin{array}{l}\text { Arguments } \\
\quad \text { against } \\
\text { policy }\end{array}$ & $\begin{array}{l}\text { - Government interference and 'nanny state' } \\
\text { intervention } \\
\text { - Threat to individual rights } \\
\text { - Threat to cultural values, e.g. right as an } \\
\text { Australian to enjoy a beer with friends and } \\
\text { restrictions seen to impinge on this } \\
\text { - Threat to commercial freedom and the } \\
\text { rights of businesses } \\
\text { - Questionable government motivation or } \\
\text { agenda for policy, e.g. policy as revenue } \\
\text { raising measure rather than for protection of } \\
\text { health } \\
\text { - Policy is unfair as it will punish the poor and } \\
\text { those who drink responsibly }\end{array}$ & $\begin{array}{l}\text { - Government interference, tobacco use is } \\
\text { legal, government attempts to regulate tobacco } \\
\text { use (e.g. through taxes), is interference } \\
\text {-Individual responsibility, tobacco use is a } \\
\text { personal choice, regulating individual } \\
\text { behaviour is not the remit of the government } \\
\text {-Threat to individual rights } \\
\text {-Threat to cultural values, e.g. ability to have } \\
\text { a cigarette with a beer in the pub is core part of } \\
\text { Australian culture } \\
\text {-Threat to commercial freedom and the } \\
\text { rights of businesses } \\
\text {-Policy as a slippery slope to further } \\
\text { intervention } \\
\text {-Moralising and stigmatising, e.g. smoking } \\
\text { as an acceptable vice; smokers should not be } \\
\text { subjected to moralising and hostile behaviour } \\
\text { by those who want to prohibit tobacco } \\
\text {-Questionable government motivation, e.g. } \\
\text { Government as inconsistent and hypocritical } \\
\text { for not allowing the use of a legal product } \\
\text { while also taxing smokers to raise revenues }\end{array}$ & $\begin{array}{l}\text { - Government interference, policy is not part of } \\
\text { the government's role or responsibility and } \\
\text { represents government overreach and 'nanny } \\
\text { state' interference } \\
\text { - Individual responsibility for regulating own } \\
\text { behaviour } \\
\text { - Threat to individual rights, impinging on free } \\
\text { choice and consumer rights; need for protection of } \\
\text { independence and individual liberties } \\
\text { - Policy as a slippery slope to more government } \\
\text { intervention } \\
\text { - Questionable government motivation, e.g. } \\
\text { policy as government attempt to raise revenue }\end{array}$ \\
\hline
\end{tabular}

response to news items about tobacco plain packaging, finding that the majority of comments opposed policy, with the dominant argument focusing on the likely ineffectiveness of the policy (Freeman, 2011).

\section{Discussion}

Policies which seek to address key risk factors at the population level are crucial to tackling the growing burden of chronic disease. To appropriately position arguments for policy interventions, public health advocates need to anticipate the arguments they will face and be equipped with the skills to position their arguments most strongly (Champion and Chapman, 2005). This study represents one of the few attempts to identify and compare how different policy interventions have been framed within the news media. Such comparative syntheses are valuable for enabling transfer of learning and insights by allowing public health advocates to draw on arguments that have been used in other policy areas, and to anticipate the counter frames they may encounter from policy opponents. A key finding from this review however, was while a relatively large number of studies have examined how policy issues are framed within the media, comparatively few have considered the impact of such framing on public attitudes towards policy intervention. This represents a significant gap in our practical understanding of how to frame policy issues in ways that are likely to engender public support.

Our analysis identified five overarching argument frames: health, societal, economic, practical and ideological. While there were nuances in terms of the specific argument frames used across the topic areas and specific policies, there were considerable similarities in the overarching arguments employed in support of and opposition to policy. Arguments in support of policy tended to rely on framing in terms of health or societal issues, while arguments in opposition of policy tended to draw on economic, practical or ideological framing of the issues.

In line with Weishaar et al. (2016) these findings indicate that proponents of policy interventions tended to draw on arguments that could be considered to reflect a social justice framing (Beauchamp, 1976), for example invoking arguments around the need to prevent risks, promote health and protect vulnerable populations from harm. Such framing aligns with the core principles of public health, protecting 
health and improving equity at the population level, and it is therefore unsurprising that such arguments are frequently used by public health advocates. However, while social justice arguments may strengthen support for policy among people who hold similar values, they may not necessarily be effective in engendering support amongst those who hold different values. As demonstrated by Gollust et al. (2009), the effectiveness of different frames varied according to the political orientation of the audience. Further research in different contexts is needed to determine which arguments will prove most effective with target audiences.

Arguments in opposition of policy tended to be framed in terms of cultural or ideological principles that reflect more of a market justice framing, drawing on principles such as individual responsibility, personal and commercial freedoms, and the appropriateness of government involvement in regulating behaviour. Challenges to these arguments were not common, such that policy advocates may to some extent be 'talking past' their opponents rather than countering their arguments directly, which may impact on the persuasiveness of arguments in support of policy. A recent study found the use of counter arguments directly attacking the specific claims of persuasive product advertising are more effective than arguments that do not specifically address the original claims (Petrova et al., 2012). Public health advocates need to be nimble and anticipate the kinds of arguments they are likely to encounter and know how to counter these.

Despite a recent proliferation of research into media framing of issues related to chronic disease, this paper shows there has been relatively little focus on how policy interventions are framed within the media, and even less consideration of the impact of such coverage on public attitudes towards policy intervention. While the steady increase in studies over time reflects a growing recognition of the importance of media framing of public health issues, 49 studies over nearly 20 years suggests that research in this area is relatively under-developed, and the paucity of research considering the impact of media coverage on attitudes towards policy interventions represents a significant gap. Moreover, the predominance of studies from the United States and on tobacco control policy, as well as a lack of comparative studies, highlights the need for more research about media representations of a range of different policy interventions and their role in public and political debates, particularly across countries with different political systems, cultural norms and societal values.

This review highlights a number of important gaps in our knowledge of how best to position public policy. The majority of studies within this review employ content analysis to classify the kinds of arguments being used in policy debates. While such approaches are valuable in highlighting arguments that can be used in different situations, more research is needed to understand the impacts of these arguments. In particular, research is lacking on how such arguments influence public attitudes towards policy interventions or play out dynamically within public discourse. Only nine studies within our sample considered the impact of issue framing on public attitudes towards policy. This is not surprising when considering the methodological challenges inherent in addressing these kinds of questions. Although experimental approaches can demonstrate the impact of a single news story on self-reported attitudes towards real or hypothetical policy scenarios, they are limited in their generalisability and are unable to take into account the complexity inherent in attitude formation in the 'real-world'. For example, the constructed news stories used within experimental studies are not representative of how information in presented in the real-world, where audiences will simultaneously encounter multiple, competing frames (Gollust et al., 2009). Innovative approaches are needed to explore the factors that influence attitudes towards policy within the context of a rich media environment, and the interplay between exposure to media coverage of policy issues, and prior knowledge, attitudes and beliefs, and social, economic and cultural context.

We found that despite the changing media landscape, there was a predominance of research on more traditional forms of media, particularly newspapers, and no studies exploring how policy debates play out within social media. This may reflect the relatively recent growth of social media and the availability of techniques for the analysis of social media data. Understanding how policy issues are being debated within these social media spaces will be crucial going forwards. Social media platforms enable greater public interaction and engagement than traditional media and provide fertile ground for examining how information diffuses and amplifies within and across networks, as well as how the public react to and interact with different kinds of policy arguments. We would expect to see a rapid growth in this area of research in the coming years.

\section{Conclusions}

Within this review we have provided a synthesis of current research on media framing of policy interventions targeting key risk factors for chronic disease and identified a number of areas for future work. Understanding how the five dominant argument frames identified in this study are applied within discourses around prevention policy may equip public health advocates with additional strategies to consider in the media to effectively promote health policies. The findings of this review indicate that while there is growing interest in this field, there is a need to explore new approaches and questions if we are to move beyond describing how arguments are framed to understanding how framing influences attitudes and opinions about public health policy.

\section{Ethics approval}

Not applicable.

\section{Consent}

Not applicable.

\section{Availability of data and material}

Not applicable.

\section{Conflicts of interest}

The authors declare that they have no competing interests.

\section{Funding}

The work was funded by the National Health and Medical Research Council of Australia (NHMRC) through its Partnership Centre grant scheme (grant GNT9100001). NSW Health, ACT Health, the Australian Government Department of Health, the Hospitals Contribution Fund of Australia and the HCF Research Foundation have contributed funds to support this work as part of the NHMRC Partnership Centre grant scheme. The contents of this paper are solely the responsibility of the individual authors and do not reflect the views of the NHMRC or funding partners.

\section{Authors' contributions}

SR and PH had the original idea for the review. The original search strategy was developed by SR, in discussion with $\mathrm{PH}$ and conducted by SR. The development of inclusion criteria and identification of articles for inclusion was undertaken jointly by MM and SR, and data extraction was led by MM and LM. Synthesis of extracted data was primary undertaken by SR, in close collaboration with MM and LM. The first draft of the paper was prepared by SR, with major contributions to further drafting from all authors. All authors read and approved the final manuscript. 


\section{Appendix A. Supplementary data}

Supplementary data to this article can be found online at https:// doi.org/10.1016/j.socscimed.2019.112428.

\section{References}

Akintola, O., Lavis, J.N., Hoskins, R., 2015. Print media coverage of primary healthcare and related research evidence in South Africa. Health Res. Policy Syst. 13 (68).

Anderson, P., De Bruijn, A., Angus, K., Gordon, R., Hastings, G., 2009. Impact of alcohol advertising and media exposure on adolescent alcohol use: a systematic review of longitudinal studies. Alcohol Alcohol 44 (3), 229-243.

Australian Institute of Health and Welfare, 2016. Australia's Health 2016. Australia's Health Series No. 15. Cat. No. AUS 199. AIHW, Canberra.

Australian Public Service Commission, 2007. Changing Behaviour: a Public Policy Perspective. ACT: APSC.

Azar, D., White, V., Bland, S., Livingston, M., Room, R., Chikritzhs, T., Wakefield, M., 2014. 'Something's brewing': the changing trends in alcohol coverage in Australian newspapers 2000-2011. Alcohol Alcohol 49 (3), 336-342. https://doi.org/10.1093/ alcalc/agt139.

Bach, L.E., Shelton, S.C., Moreland-Russell, S., Israel, K., 2013. Smoke-free workplace ballot campaigns: case studies from Missouri and lessons for policy and media advocacy. Am. J. Health Promot. 27 (6), e124-133.

Barry, C.L., Brescoll, V.L., Gollust, S.E., 2013. Framing childhood obesity: how individualizing the problem affects public support for prevention. Political Psychol. 34 (3), 327-349. https://doi.org/10.1111/pops.12018.

Beauchamp, D.E., 1976. Public health as social justice. Inquiry 13 (1), 3-14.

Blake, K.D., Kaufman, A.R., Lorenzo, J., Augustson, E.M., 2015. A descriptive study of television news coverage of tobacco in the United States: frequency of topics, frames, exemplars, and efficacy. J. Health Commun. 20 (12), 1415-1421. https://doi.org/10. $1080 / 10810730.2015 .1018651$.

Bloom, D., Cafiero, E., Jané-Llopis, E., Abrahams-Gessel, S., Bloom, L., Fathima, S., Mowafi, M., 2012. The Global Economic Burden of Noncommunicable Diseases. World Economic Forum, Geneva.

Braun, V., Clarke, V., 2006. Using thematic analysis in psychology. Qual. Res. Psychol. 3 (2), 77-101. https://doi.org/10.1191/1478088706qp063oa.

Burstein, P., 2003. The impact of public opinion on public policy: a review and an agenda. Political Res. Q. 56 (1), 29-40. https://doi.org/10.1177/106591290305600103.

Champion, D., Chapman, S., 2005. Framing pub smoking bans: an analysis of Australian print news media coverage, March 1996-March 2003. J. Epidemiol. Community Health 59 (8), 679-684. https://doi.org/10.1136/jech.2005.035915.

Coleman, R., Thorson, E., Wilkins, L., 2011. Testing the effect of framing and sourcing in health news stories. J. Health Commun. 16 (9), 941-954. https://doi.org/10.1080/ 10810730.2011.561918.

Donaldson, E.A., Cohen, J.E., Truant, P.L., Rutkow, L., Kanarek, N.F., Barry, C.L., 2015. News media framing of New York City's sugar-sweetened beverage portion-size cap. Am. J. Publ. Health 105 (11), 2202-2209. https://doi.org/10.2105/AJPH.2015. 302673.

Durrant, R., Wakefield, M., McLeod, K., Clegg-Smith, K., Chapman, S., 2003. Tobacco in the news: an analysis of newspaper coverage of tobacco issues in Australia, 2001. Tob. Control 12 (Suppl. 2), ii75-81. https://doi.org/10.1136/tc.12.suppl_2.ii75.

Entman, R.M., 1993. Framing: toward clarification of a fractured paradigm. J. Commun. 43 (4), 51-58. https://doi.org/10.1111/j.1460-2466.1993.tb01304.x.

Fan, D.P., 1996. News media framing sets public opinion that drugs is the country's most important problem. Subst. Use Misuse 31 (10), 1413-1421. https://doi.org/10.3109/ 10826089609063984.

Fogarty, A.S., Chapman, S., 2011. Framing and the marginalisation of evidence in media reportage of policy debate about alcopops, Australia 2008-2009: implications for advocacy. Drug Alcohol Rev. 30 (6), 569-576. https://doi.org/10.1111/j.1465-3362. 2010.00253.x.

Fogarty, A.S., Chapman, S., 2012a. Advocates, interest groups and Australian news coverage of alcohol advertising restrictions: content and framing analysis. BMC Public Health $12,727$.

Fogarty, A.S., Chapman, S., 2012b. Australian television news coverage of alcohol, health and related policies, 2005 to 2010: implications for alcohol policy advocates. Aust. N. Z. J. Public Health 36 (6), 530-536.

Freeman, B., 2011. Tobacco plain packaging legislation: a content analysis of commentary posted on Australian online news. Tob. Control 20 (5), 361-366. https://doi.org/ $10.1136 /$ tc. 2011.042986.

Freeman, B., Chapman, S., Storey, P., 2008. Banning smoking in cars carrying children: an analytical history of a public health advocacy campaign. Aust. N. Z. J. Public Health 32 (1), 60-65. https://doi.org/10.1111/j.1753-6405.2008.00167.x.

Frieden, T.R., 2014. Six components necessary for effective public health program implementation. Am. J. Publ. Health 104 (1), 17-22.

Gollust, S.E., Lantz, P.M., Ubel, P.A., 2009. The polarizing effect of news media messages about the social determinants of health. Am. J. Publ. Health 99 (12), 2160-2167. https://doi.org/10.2105/AJPH.2009.161414.

Harwood, E.M., Witson, J.C., Fan, D.P., Wagenaar, A.C., 2005. Media advocacy and underage drinking policies: a study of Louisiana news media from 1994 through 2003. Health Promot. Pract. 6 (3), 246-257.

Hawkins, B., Holden, C., 2013. Framing the alcohol policy debate: industry actors and the regulation of the UK beverage alcohol market. Crit. Policy Stud. 7 (1), 53-71. https:// doi.org/10.1080/19460171.2013.766023.

Hellman, M., Karlsson, T., 2012. In fear of a reversal back to the spirits-drinking era-The
2004 decrease of Finnish alcohol taxes in public discourse. Nordic Studies on Alcohol and Drugs 29 (1), 57-77.

Henderson, J., Coveney, J., Ward, P., Taylor, A., 2009. Governing childhood obesity: framing regulation of fast food advertising in the Australian print media. Soc. Sci. Med. 69 (9), 1402-1408.

Hilton, S., Wood, K., Bain, J., Patterson, C., Duffy, S., Semple, S., 2014. Newsprint coverage of smoking in cars carrying children: a case study of public and scientific opinion driving the policy debate. BMC Public Health 14, 1116. https://doi.org/10. 1186/1471-2458-14-1116.

Jarlenski, M., Barry, C.L., 2013. News media coverage of trans fat: health risks and policy responses. Health Communication 28 (3), 209-216.

Katikireddi, S.V., Bond, L., Hilton, S., 2014. Changing policy framing as a deliberate strategy for public health advocacy: a qualitative policy case study of minimum unit pricing of alcohol. Milbank Q. 92 (2), 250-283. https://doi.org/10.1111/1468-0009. 12057.

Kitzinger, J., 2004. Framing Abuse: Media Influence and Public Understanding of Sexual Violence against Children. Pluto Press, London.

Kothari, A., Gore, D., MacDonald, M., Bursey, G., Allan, D., Scarr, J., The Renewal of Public Health Systems Research, T, 2013. Chronic disease prevention policy in British Columbia and Ontario in light of public health renewal: a comparative policy analysis. BMC Public Health 13 (1). https://doi.org/10.1186/1471-2458-13-934. 934934.

Lawhon, M., Herrick, C., 2013. Alcohol control in the news: the politics of media representations of alcohol policy in South Africa. J. Health Politics Policy Law 38 (5), 987-1021.

Lemmens, P.H., Vaeth, P.A., Greenfield, T.K., 1999. Coverage of beverage alcohol issues in the print media in the United States, 1985-1991. American Journal of Public Health 89 (10), 1555-1560.

Lima, J.C., Siegel, M., 1999. The tobacco settlement: an analysis of newspaper coverage of a national policy debate, 1997-98. Tob. Control 8 (3), 247-253.

Long, M., Slater, M.D., Lysengen, L., 2006. US news media coverage of tobacco control issues. Tob. Control 15 (5), 367-372.

Magnusson, R.S., 2015. Case studies in nanny state name-calling: what can we learn? Public Health 129 (8), 1074-1082. https://doi.org/10.1016/j.puhe.2015.04.023.

Magzamen, S., Charlesworth, A., Glantz, S.A., 2001. Print media coverage of California's smokefree bar law. Tob. Control 10 (2), 154-160. https://doi.org/10.1136/tc.10.2. 154.

Mayes, R., Armistead, B., 2013. Chronic disease, prevention policy, and the future of public health and primary care. Med. Healthc. Philos. 16 (4), 691-697. https://doi. org/10.1007/s11019-012-9454-0.

McDaniel, P.A., Offen, N., Yerger, V., Forsyth, S., Malone, R.E., 2015. "Tired of watching customers walk out the door because of the smoke": a content analysis of media coverage of voluntarily smokefree restaurants and bars. BMC Public Health 15, 761.

McGee, R., Bang, S., Marsh, L., 2014. Newspaper coverage of tobacco control in New Zealand. Aust. N. Z. J. Public Health 38 (3), 265-269.

McLeod, K., Wakefield, M., Chapman, S., Smith, K.C., Durkin, S., 2009. Changes in the news representation of smokers and tobacco-related media advocacy from 1995 to 2005 in Australia. J. Epidemiol. Community Health 63 (3), 215-220.

Moore, M., Yeatman, H., Davey, R., 2015. Which nanny - the state or industry? Wowsers, teetotallers and the fun police in public health advocacy. Public Health 129 (8), 1030-1037. https://doi.org/10.1016/j.puhe.2015.01.031.

Morrison, S.D., Sutton, S.F., Mebane, F.E., 2006. Public health news frames in North Carolina newspaper coverage of the $100 \%$ Tobacco-Free Schools campaign? Sometimes. North Carolina Medical Journal 67 (4), 255-259.

Moshrefzadeh, A., Rice, W., Pederson, A., Okoli, C.T.C., 2013. A content analysis of media coverage of the introduction of a smoke-free bylaw in Vancouver parks and beaches. Int. J. Environ. Res. Public Health 10 (9), 4444-4453.

Nagelhout, G.E., Putte, B. v. d., Vries, H. d., Crone, M., Fong, G.T., Willemsen, M.C., 2012. The influence of newspaper coverage and a media campaign on smokers' support for smoke-free bars and restaurants and on secondhand smoke harm awareness: findings from the International Tobacco Control (ITC) Netherlands Survey. Tob. Control 21 (1), 24-29.

Niederdeppe, J., Gollust, S.E., Jarlenski, M.P., Nathanson, A.M., Barry, C.L., 2013. News coverage of sugar-sweetened beverage taxes: pro- and antitax arguments in public discourse. Am. J. Publ. Health 103 (6), e92-98.

Nutbeam, D., Kickbusch, I., 1998. Health promotion glossary. Health Promot. Int. 13 (4), 349-364. https://doi.org/10.1093/heapro/13.4.349.

Otten, A.L., 1992. The influence of the mass media on health policy. Health Aff. 11 (4), 111-118.

Page, B.I., Shapiro, R.Y., 1983. Effects of public opinion on policy. Am. Pol. Sci. Rev. 77 (1), 175-190. https://doi.org/10.2307/1956018.

Patterson, C., Katikireddi, S.V., Wood, K., Hilton, S., 2015a. Representations of minimum unit pricing for alcohol in UK newspapers: a case study of a public health policy debate. J. Public Health 37 (1), 40-49.

Patterson, C., Semple, S., Wood, K., Duffy, S., Hilton, S., 2015b. A quantitative content analysis of UK newsprint coverage of proposed legislation to prohibit smoking in private vehicles carrying children. BMC Public Health 15, 760. https://doi.org/10. 1186/s12889-015-2110-x.

Petrova, P.K., Cialdini, R.B., Goldstein, N.J., Griskevicius, N., 2012. Protecting Consumers from Harmful Advertising: what Constitutes an Effective Counter Argument? Retrieved from. https://pdfs.semanticscholar.org/b38f/ 3aabffdae30d5e453a1794458e4e98eb1a6d.pdf.

Rowbotham, S., Astell-Burt, T., Barakat, T., Hawe, P., 2019. 30 + years of media analyses of relevance to chronic disease: A scoping review. BMC Public Health Submitted for publication.

Russell, A., Dwidar, M., Jones, B.D., 2016. The mass media and the policy process. In: 
Oxford University Press.

Soroka, S.N., Wlezien, C., 2010. Degrees of Democracy: Politics, Public Opinion, and Policy. Cambridge University Press, Cambridge.

Tewksbury, D., Scheufele, D.A., 2009. News framing theory and research. In: Bryant, J., Oliver, M.B. (Eds.), Media Effects: Advances in Theory and Research. Erlbaum, Hillsdale, NJ, pp. 17-33.

Thrasher, J.F., Kim, S.H., Rose, I., Navarro, A., Craft, M.K., Davis, K.J., Biggers, S., 2014. Print media coverage around failed and successful tobacco tax initiatives: the South Carolina experience. Am. J. Health Promot. 29 (1), 29-36.

Vos, T., Carter, R., Barendregt, J., Mihalopoulos, C., Veerman, L., Magnus, A., Wallace, A., 2010. Assessing Cost-Effectiveness in Prevention: ACE-Prevention September 2010 Final Report. University of Queensland.

Wackowski, O.A., Lewis, M.J., Delnevo, C.D., Ling, P.M., 2013. A content analysis of smokeless tobacco coverage in U.S. newspapers and news wires. Nicotine Tob. Res. 15 (7), 1289-1296.

Wackowski, O.A., Lewis, M.J., Hrywna, M., 2011. Banning smoking in New Jersey casinos - a content analysis of the debate in print media. Subst. Misuse 46 (7), 882-888.

Wakefield, M., McLeod, K., Smith, K.C., 2003. Individual versus corporate responsibility for smoking-related illness: Australian press coverage of the Rolah McCabe trial.
Health Promot. Int. 18 (4), 297-305.

Weishaar, H., Dorfman, L., Freudenberg, N., Hawkins, B., Smith, K., Razum, O., Hilton, S., 2016. Why media representations of corporations matter for public health policy: a scoping review. BMC Public Health 16 (1), 899. https://doi.org/10.1186/s12889016-3594-8.

Wise, D., Brewer, P.R., 2010. Competing frames for a public health issue and their effects on public opinion. Mass Commun. Soc. 13 (4), 435-457.

Wood, K., Patterson, C., Katikireddi, S.V., Hilton, S., 2014. Harms to 'others' from alcohol consumption in the minimum unit pricing policy debate: a qualitative content analysis of U.K. newspapers (2005-12). Addiction 109 (4), 578-584. https://doi.org/10. 1111/add.12427.

World Health Organization, 2013. Economics of the Social Determinants of Health and Health Inequalities: a Resource Book, vol. 2013 World Health Organization, Geneva.

World Health Organization, 2014. Global Status Report on Noncommunicable Diseases 2014. Geneva, Switzerland, vol. 2014 World Health Organization.

Wutzke, S., Morrice, E., Benton, M., Wilson, A., 2017. What will it take to improve prevention of chronic diseases in Australia? A case study of two national approaches. Aust. Health Rev. 41 (2), 176-181. https://doi.org/10.1071/AH16002. 